\title{
Adenocarcinoma de Reto com Metástase para Mandíbula: Relato de Caso
}

\section{Metastatic Adenocarcinoma from the Rectum to the Mandible: A Case Report}

\author{
FLÁVIA BALSAMO'; GALDINO JOSÉ SITONIO FORMIGA²
}

${ }^{1}$ Assistente do Serviço de Coloproctologia do Hospital Heliópolis, São Paulo- S.P., TSBCP. ${ }^{2}$ Chefe do Serviço de Coloproctologia do Hospital Heliópolis, São Paulo- S.P., TSBCP

BALSAMO F; FORMIGA GJS. Adenocarcinoma de Reto com Metástase para Mandíbula: Relato de Caso. Rev bras Coloproct, 2009;29(4): 493-496.

RESUMO: Os autores relatam um caso de metástase de adenocarcinoma de reto para mandíbula, manifestação de rara incidência e que é sub-diagnosticada. Demonstram a radioterapia local como paliação e recuperação da função mastigatória.

Descritores: Metástase, disseminação, adenocarcinoma, inoculação de neoplasia, cirurgia colorretal.

\section{INTRODUÇÃO}

Tumorações malignas do aparelho mastigatório são incomuns e doença metastática para estas localidades são ainda menos freqüentes ${ }^{1-6}$.

Metástases ósseas são mais facilmente encontradas em neoplasias de mamas, pulmões, rins, tireóide e próstata, que são órgãos que têm uma propensão para metastatizar para esta localidade ${ }^{1,2,4-6}$.

Metástases de adenocarcinoma de reto para a mandíbula são raras e sua real incidência provavelmente é subestimada ${ }^{4-6}$.

Poucos são os estudos que se referem ao mecanismo de aparecimento das metástases de adenocarcinoma retal e há dificuldades para a identificação e diferenciação entre lesões primárias da mandíbula e lesões metastáticas ${ }^{2,6}$.

$\mathrm{O}$ objetivo deste relato deve-se à raridade de tal entidade, bem como a forma de abordagem diagnóstica e terapêutica.

\section{RELATO DO CASO}

T. I. S., 59 anos, feminino, branca, natural da Paraíba e procedente de São Paulo, S.P. Há quatro meses apresentando hematoquesia, puxo, tenesmo, mucorréia e afilamento das fezes, associado a emagrecimento de $10 \mathrm{Kg}$, dor ao evacuar e alteração do hábito intestinal de uma cada quatro dias. Há uma semana com queixa de abaulamento da região mandibular direita, dificuldade à abertura da boca e mastigação.

Ao exame físico da face com nodulação endurecida de $5 \times 4 \mathrm{~cm}$ nos seus maiores eixos, palpável em região têmporo-mandibular direita, endurecida, fixa, dolorosa e limitação à abertura da boca. Cavidade oral com abaulamento na região correspondente aos últimos molares inferiores, sem comprometimento da mucosa.

Ao exame proctológico evidenciada lesão úlcero-vegetante póstero lateral direita com extensão de dois a sete centímetros da borda anal, amolecida, fixa e com sinais sugestivos de invasão esfíncteriana. $\mathrm{O}$ exame histo-patológico revelou tratar-se de adenocarcinoma.

Durante o estadiamento não foram encontradas lesões sincrônicas no cólon ou doença metastática para o fígado, porém em exames radiológicos foram identificadas deformidade de face e lesão lítica de mandíbula, ambas à direita. (Figuras 1a e 1b) 

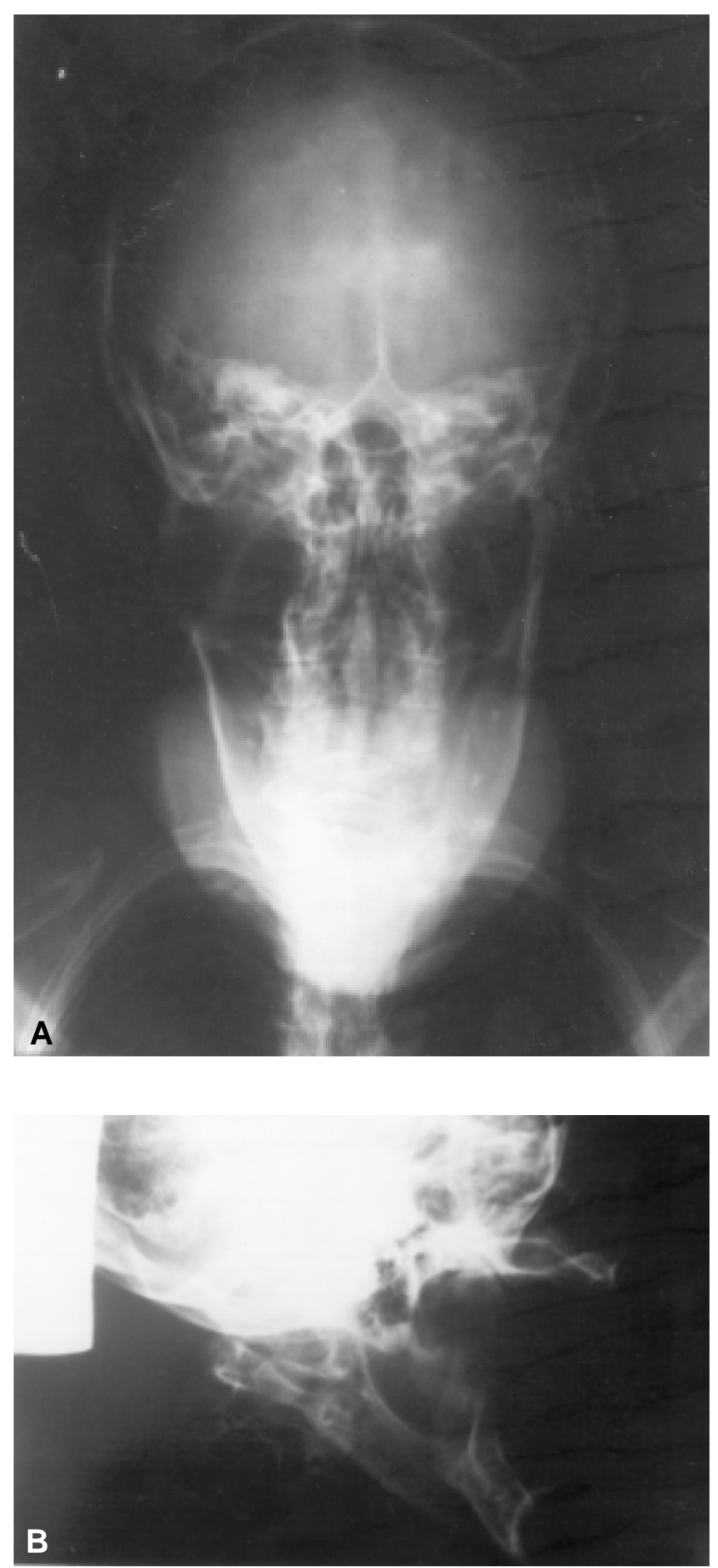

Figuras 1 a e 1 b - RX com deformidade de face à direita.

O estudo tomográfico evidenciou lesões nodulares múltiplas em ambos os pulmões e espessamento concêntrico da parede retal, além de lesão hipoatenuante em topografia de mandíbula e parótida direita, com invasão de conduto auditivo direito (Figura 2), a qual já nos referimos anteriormente.

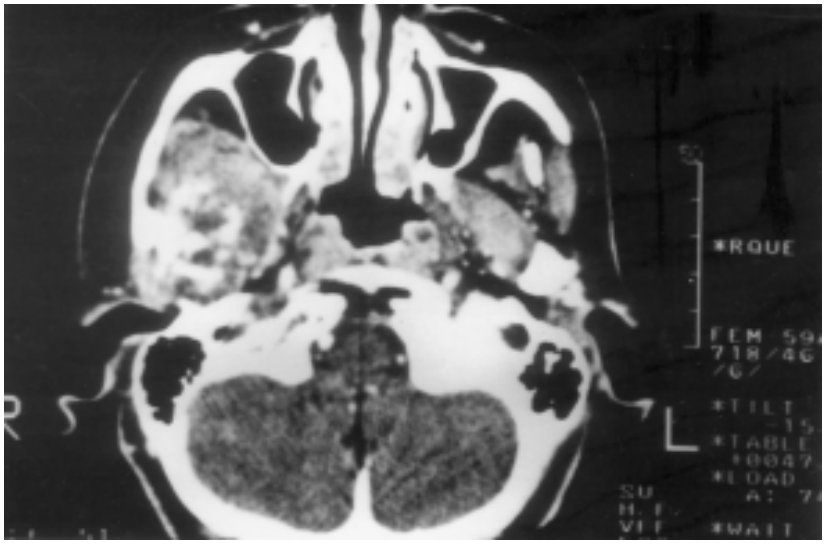

Figura 2 - TC com invasão de conduto auditivo direito.

A confirmação diagnóstica foi obtida através de biópsia por punção de agulha fina na região correspondente ao abaulamento de face e que identificou infiltração óssea por adenocarcinoma metastático. (Figuras $3 \mathrm{a}$ e $3 \mathrm{~b}$ )

Houve necessidade de individualizar o tratamento, neste caso, já que a paciente descrita, além de apresentar neoplasia maligna de reto com metástases pulmonares, também apresenta metástase óssea para a mandíbula. Esta última por ser causa principal de dor, desconforto e limitação da função mastigatória foi o motivo principal de suas queixas e de sua precária qualidade de vida.

Fez-se opção pela realização de radioterapia em face utilizando-se 5000 cGy nesta localização e quimioterapia sistêmica paliativa com o 5-Fluorouracil e Leucovorin, visando o controle das metástases pulmonares. Em relação à lesão retal, optou-se pela realização de derivação intestinal, pois apresentava quadros suboclusivos.

Evoluiu com restauração da função mastigatória após a radioterapia, porém apresentou neutropenia irreversível após segunda sessão de quimioterapia, com óbito três meses após o diagnóstico das lesões.

\section{DISCUSSÃO}

As metástases ósseas de adenocarcinoma de reto são encontradas em apenas $1 \%$ dos casos ${ }^{3-5,5,7,8}$

As neoplasias retais podem metastatizar para os ossos de duas formas: via fígado através da circulação mesentérico-portal ou, passando através das veias retais para o plexo venoso vertebral. No último caso, o 

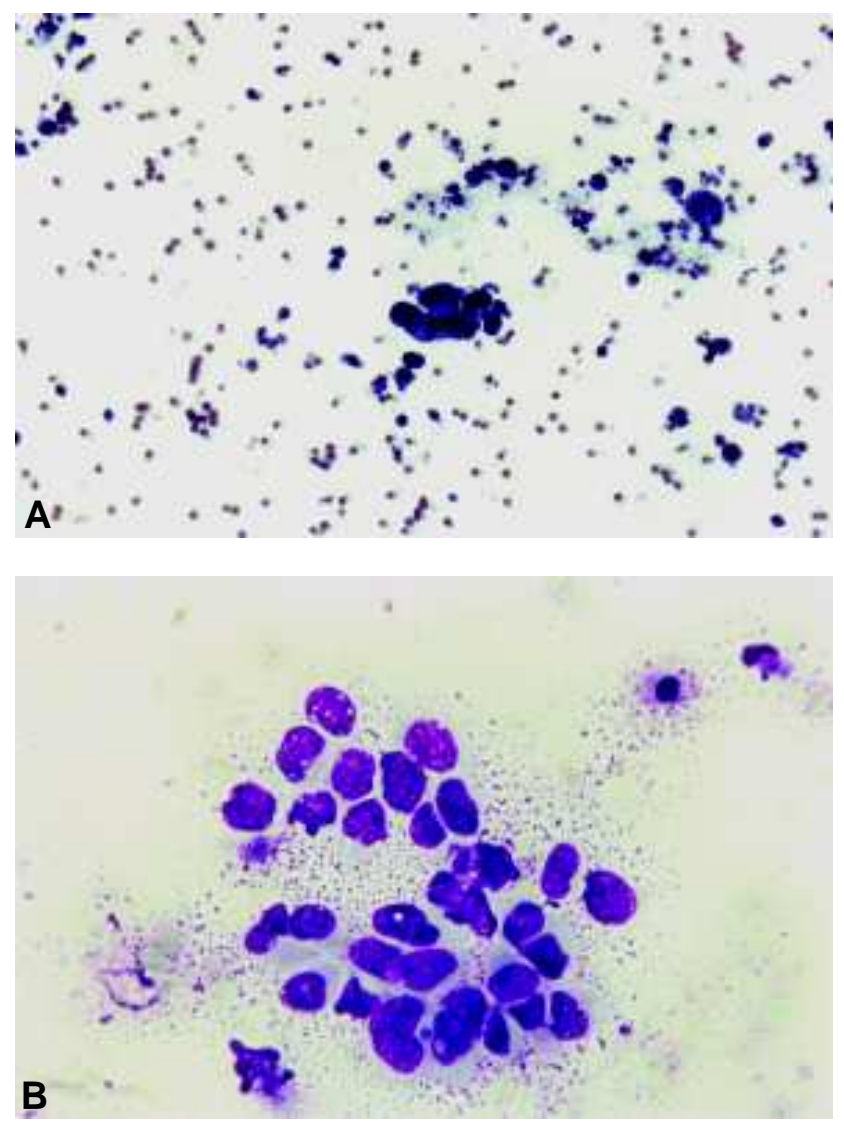

Figuras $3 \boldsymbol{a}$ e $\mathbf{3 b}$ - Infiltração por adenocarcinoma (aumento de 10 e 20x).

cérebro e os pulmões podem estar envolvidos antes do fígado. O plexo venoso vertebral parece ser a rota de preferência para a disseminação metastática para os ossos e para o sistema nervoso central ${ }^{6}$.

A disseminação cancerígena, portanto, ocorre principalmente através da via hematogênica. $\mathrm{O}$ tumor acessa os vasos sanguíneos através de invasão direta aos mesmos no sítio primário da lesão. Podem atingir a mandíbula através da circulação venosa vertebral ou circulação portal. Na circulação vertebral as células tumorais podem passar da veia jugular para a veia cervical, atingindo a mandíbula. Na disseminação por- tal as células tumorais atingem as veias mesentéricas e drenam para o sistema portal, podendo progredir para o fígado, coração direito, pulmões, coração esquerdo e finalmente a artéria carótida, podendo penetrar os ossos através de suas arteríolas nutridoras ${ }^{4}$.

Quando a mandíbula é afetada, as metástases ocorrem preferencialmente na articulação têmporomandibular devido à disseminação neoplásica para o côndilo mandibular que é rico em medula vermelha ${ }^{6}$.

A raridade do acometimento metastático do aparelho ósseo mastigatório pelo adenocarcinoma de reto pode ser consequência do fato de que a mandíbula é raramente examinada e, além disto, as metástases aí disseminadas podem espalhar-se intrinsecamente ${ }^{6,7}$.

A sintomatologia predominante consiste em dor e tumefação local, além de distúrbios da mastigação e trisma $^{2}$.

Clausen e Poulsen ${ }^{2}$ em 1963, propuseram um critério para definir tumores ósseos metastáticos: em primeiro lugar, é preciso que se trate de metástase verdadeira, localizada originalmente em tecido ósseo e não invasão por contigüidade de tumores de outras localidades. Em segundo lugar, a lesão tem que ser microscopicamente identificada como carcinoma e, finalmente, o tumor primário precisa ser identificado ${ }^{2,3}$.

O diagnóstico deve ser, portanto, confirmado através de exame histopatológico por biópsia de agulha fina, tendo sido relatado como método mais importante ${ }^{6,8}$.

A radioterapia local pode ser utilizada paliativamente, permitindo diminuição da dor e resgatando parcialmente a função mastigatória ${ }^{4,6}$.

Ressaltamos que a doença metastática para mandíbula deve ser pesquisada em pacientes com adenocarcinoma colorretal através de exame local detalhado. Em casos de pacientes com abaulamento e ou dor em mandíbula, a investigação com exames subsidiários é necessária e o tratamento paliativo com radioterapia local tem finalidade principal de alívio da sintomatologia.

ABSTRACT: The authors report a case of metastatic adenocarcinoma of the rectum to the mandible, a rare presentation of the disease that is almost always underestimated. Authors demonstrate local radiotherapy for palliation with recovery of the masticatory function.

Key words: Metastasis, dissemination, adenocarcinoma, neoplasm seeding, colorectal surgery. 


\section{REFERÊNCIAS}

1. CastiglianoSC, Rominger $\mathbf{J}$ - Metastatic malignancy of the jaws. Am J Surg; 1954,87: 496-507.

2. Clausen F, Poulsen $\mathrm{H}$ - Metastatic carcinoma of the jaws. Acta Pathol. Microbiol. Scand; 1963,57:361-374.

3. Delfino JJ, Wilson TK, Rainero DM - Metastatic adenocarcinoma from the colon to the mandible. J.Oral Maxilofac. Surg; 1981,40:188-190.

4. Mast HL, Nissenblatt MJ - Metastatic colon carcinoma to the jaw: a case report and review of the literature. J.Surg.Oncol; 1987,34: 202-207.

5. Macafee KA, Quinn PD, Abaza NA-Adenocarcinoma of the colon metastatic to the temporomandibular joint: a case report. J. Oral-Maxilofac. Surg; 1993,51:793-797.

6. Balestreri L, Canzioneri V, Innocente R, Cattelan A, Perin T Temporomandibular joint metastasis from rectal carcinoma:
CT findings before and after radiotherapy. A case report. Tumori; 1997,83:718-720.

7. Bentley RP, Worrall SF-Carcinoma of the colon with mandible and liver metastases. Br J Oral Maxilofac Surg; 1997, 35(3): 221-222.

8. Sheen AJ, Drake D, Langton S, Sherlock DJ - Unusual bony colorectal metástases in post-hepatometastasectomy patients. J Hepatobiliary Pancreat Surg; 2002,9(3): 379-382.

\section{Endereço para correspondência:}

FLÁVIA BALSAMO

Serviço de Coloproctologia do Hospital Heliópolis

R. Cônego Xavier, 276- Vila Heliópolis

04231-030- São Paulo, SP

Tel.: 11- 2274-7600 (ramal 244)

E-mail: flabal@uol.com.br 